\title{
Hormone
} Research

J.L. Leahy, N.G. Clark, W.T. Cefalu

\section{Medical Management of Diabetes mellitus}

New York, Marcel Dekker, 2000

738 pp., USD 99.75

ISBN 0-8247-8857-5

The monograph edited by Leahy, Clark and Cefalu is the latest volume of the programme 'Clinical Guides to Medical Management'. It is intended to bridge the gap between primary care providers and experts in the field of diabetes. The current volume provides a comprehensive, up-to-date review of diabetes mellitus for practising providers and physicians in training. The format is different from that of many other textbooks. Physiology, biochemistry, anatomy and molecular biology are kept quite short. Instead of the encyclopaedic format, the authors try to outline the most effective diagnostic and therapeutic approaches to clinical problems.

The first part of the book is an overview and provides a background into the general subject. What is diabetes? How is it diag- nosed? The second part describes signs, symptoms and diagnosis of type 1 and type 2 diabetes. Part 3 covers traditional and novel therapeutic regimens. Part 4 focuses on complications. Part 5 addresses special clinical settings like diabetes in the elderly or in hospitalized patients.

The book includes rare symptoms as well as latest developments. Some details may be a matter of controversial debate among specialists, e.g. the therapeutic goal for treatment of childhood diabetes: HbA-1-c $8 \%$ or less. However, for practising physicians the guide gives sufficient help treating patients in the office. The references given at the end of each chapter are helpful for those who would like to extend their knowledge on special topics. Figures and tables are numerous and mainly clear. Although the pictures are black-andwhite, they give a sufficient insight.

The new volume may serve physicians to get familiar with new clinical information and provide effective treatment to patients with diabetes.

A. Neu, Tübingen

\section{KARGER}

(C) 2001 S. Karger AG, Basel

Fax +41613061234 E-Mail karger@karger.ch www. karger.com 